\title{
Ticarcillin in the treatment of experimental pseudomonas keratitis
}

\author{
A. AHMAD, G. SMOLIN, M. OKUMOTO, AND S. OHNO \\ From the Francis I. Proctor Foundation for Research in Ophthalmology and the Department of \\ Ophthalmology, University of California, San Francisco
}

SUMmary In rabbits with experimental Pseudomonas aeruginosa keratitis the subconjunctival administration of either ticarcillin or gentamicin significantly ameliorated the keratitis and reduced the number of organisms to be found in the cornea. The use of these drugs in combination had an additive effect in in vitro studies and a significantly more beneficial effect on the clinical disease than the use of either drug alone.

Ticarcillin ( $\alpha$-carboxyl-3-thienylmethyl penicillin, BRL-2288) is a semi-synthetic penicillin with an antibacterial spectrum similar to carbenicillin's. Like carbenicillin it is active against pseudomonas, and it has the additional merit of being twice as active (Neu and Garvey, 1975; Wise and Reeves, 1974). Gentamicin, which is commonly used to combat pseudomonas keratitis and is effective, has several disadvantages. It is irritating when given either topically or subconjunctivally; it may cause necrosis of the conjunctiva with subsequent scarring if given subconjunctivally; it is nephrotoxic when given systemically, and possibly when given by lavage; and gentamicin-resistant strains of pseudomonas are increasing in number (Maliwan et al., 1975). Ticarcillin's chief advantage over gentamicin is that it is not nephrotoxic and can therefore be used in high doses for long periods of time-a point of special importance to patients with severe renal failure (Davies et al., 1974).

In this study the effect of ticarcillin on pseudomonas keratitis in rabbits was evaluated and compared with the effect of gentamicin. The possible advantage of using combined ticarcillin and gentamicin was also explored.

\section{Materials and methods}

\section{IN-VITRO TESTING}

Both the minimal inhibitory concentration (MIC) and the minimal bactericidal concentration (MBC)

Supported in part by Grants EY-01121, EY-01597, and EY-00094 from the National Institutes of Health, Bethesda, Md., and in part by an unrestricted grant from Research to Prevent Blindness, Inc., New York City.

Address for reprints: Dr G. Smolin, Francis I. Proctor Foundation, University of California San Francisco, San Francisco, California 94143, USA. of ticarcillin, carbenicillin, and gentamicin were determined by means of a 24-hour broth culture of Pseudomonas aeruginosa (El Salvador strain no. 4, pyocine type no. 6) that had been incubated at $37^{\circ}$. We used a 1000-fold dilution of the culture, estimated to contain $10^{6}$ organisms $/ \mathrm{ml}$. Throughout the experiment we used this particular strain because it is effective in producing keratitis in rabbits (Smolin et al., 1974).

To test the possibility that combining ticarcillin and gentamicin might have a synergistic effect we compared the growth curves of the organism in the presence of ticarcillin alone, gentamicin alone, ticarcillin and gentamicin combined, and when there had been no exposure to an antibiotic. Counts of the number of viable organisms per millilitre were made at 3, 7, and 24 hours.

\section{IN-VIVO TESTING}

The experimental animals were 32 New Zealand white male rabbits weighing approximately $2 \mathrm{~kg}$ each. Pseudomonas keratitis was induced in both eyes of 28 rabbits by a method previously described (Smolin et al., 1974). (The other four animals were used later for toxicity tests.) After anaesthetising the eyes with $0.5 \%$ proparacaine hydrochloride we filled the cup of a toothed chalazion curette with organisms from a 24-hour culture of pseudomonas and made a single $8-\mathrm{mm}$ central scarification that penetrated the superficial stroma.

After the pseudomonas inoculation we graded the corneal lesions daily for four days according to their size and density, as follows:

$0=$ No effect;

$1+=\mathrm{Up}$ to $33 \%$ of the cornea affected;

$2+=34$ to $66 \%$ of the cornea affected;

$3+=67$ to $100 \%$ of the cornea affected. 
These scores were modified according to the density of the corneal lesion as follows: Nothing was added to the score if the lesion was nebulous, $1+$ was added if it was macular, and $2+$ was added if it was leukomatous. In this way the final score ranged from 0 to $5+$.

After instilling a drop of anaesthetic in both eyes of each animal, we gave the animals in each group a single daily subconjunctival injection, as follows:

Group 1: Ticarcillin, $2.5 \mathrm{mg}(0.2 \mathrm{ml}$ of a $12.5 \mathrm{mg} /$ ml solution);

Group 2: Gentamicin, $1.6 \mathrm{mg}(0.2 \mathrm{ml}$ of an 8.0 $\mathrm{mg} / \mathrm{ml}$ solution);

Group 3: Ticarcillin , $1.2 \mathrm{mg}(0.1 \mathrm{ml}$ of a $12.5 \mathrm{mg} /$ $\mathrm{ml}$ solution) combined with gentamicin, $0.8 \mathrm{mg}(0.1 \mathrm{ml}$ of an $8.0 \mathrm{mg} / \mathrm{ml} \mathrm{solu}$ tion);

Group 4: Saline solution, $0 \cdot 2 \mathrm{ml}$.

These doses were selected on the basis of an earlier pilot study in which we found that pseudomonas could not be recovered after three days of treatment with ticarcillin in doses of 10,40 , or $160 \mathrm{mg}$, but could be recovered after doses of 2.5 and $5.0 \mathrm{mg}$; and that the organism could not be recovered after three days of treatment with gentamicin in doses of 3.2 and $6.4 \mathrm{mg}$, but could be recovered after doses of $0.1,0.4$, and $1.6 \mathrm{mg}$. Since we needed at least minimal growth of the organism in order to compare the results of using each antibiotic alone with using the two in combination, we gave the doses listed (ticarcillin $2.5 \mathrm{mg}$, and gentamicin $1.6 \mathrm{mg}$ ).

The animals were given these injections and their lesions were graded for three days. On day 4 no treatment was given and all of the animals were killed. All of the corneas were removed, ground separately, and cultured on Mueller-Hinton plates. The colonies of pseudomonas on the plates were then counted.

\section{TOXICITY}

We tested the toxicity of ticarcillin by injecting both eyes of the four remaining (uninfected) rabbits with $10,25,50$, and $100 \mathrm{mg}$ of ticarcillin subconjunctivally. Each rabbit received one of these doses in both eyes daily for three consecutive days. For two weeks the rabbits' conjunctivas and corneas were examined daily for any adverse effects.

\section{Results}

IN-VITRO TESTING

The minimal inhibitory concentrations (MIC) of the three drugs tested were as follows: Ticarcillin, $50 \mu \mathrm{g} / \mathrm{ml}$, carbenicillin, $100 \mu \mathrm{g} / \mathrm{ml}$; and gentamicin, $0.2 \mu \mathrm{g} / \mathrm{ml}$. The minimal bactericidal concentrations (MBC) were as follows: Ticarcillin, $100 \mu \mathrm{g} / \mathrm{ml}$; carbenicillin, $200 \mu \mathrm{g} / \mathrm{ml}$; and gentamicin, $0.2 \mu \mathrm{g} / \mathrm{ml}$.

In Fig. 1 we show the growth curves of the organism in the presence of ticarcillin, gentamicin, combined ticarcillin and gentamicin, and when no antibiotic was used. In these growth studies the concentrations of the antibiotics were lower than their MICs. In the control group and gentamicin group the growth curves were the same. In the ticarcillin group there was a 1000 -fold reduction in the number of viable organisms after 24 hours, and in the combined ticarcillin and gentamicin group there was a 100 -fold greater reduction in this number after 24 hours.

\section{IN-VIVO TESTING}

Table 1 shows the results of the clinical scoring of the experimental keratitis on four successive days. In order to compare the severity of the keratitis in the four treatment groups the number of eyes with the same score in each group on day 4 were added together (Table 2). To make a statistical comparison of the results, we divided the keratitis into two categories: Mild for scores 0 to 2, and severe for scores 3 to 5 . The data were then subjected to Fisher's exact probability test.

There were significant differences between the groups treated with either ticarcillin alone or gentamicin alone and the group treated with saline solution $(\mathrm{P}<0.05)$, and a greater difference between the group treated with ticarcillin and gentamicin combined and the group treated with saline solution $(P<0.01)$. There were also significant differences between the groups treated with ticarcillin alone or gentamicin alone and the group treated with the drugs in combination $(P<0.05)$. Only between the

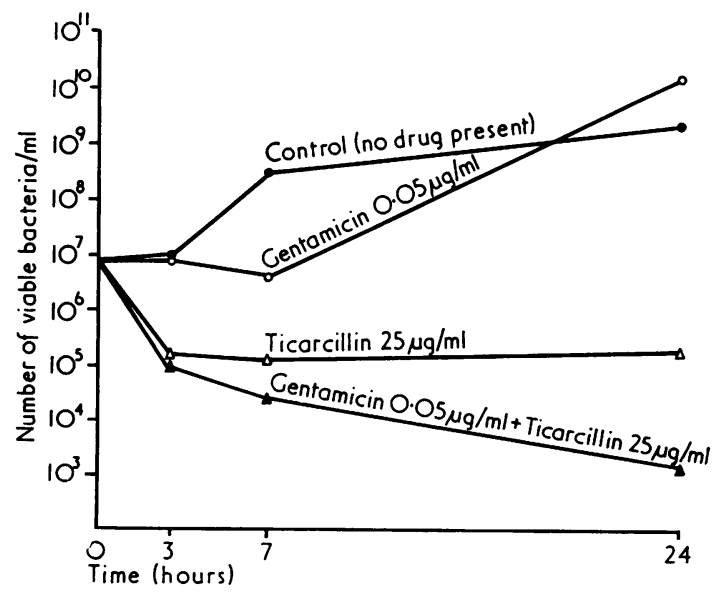

Fig. 1 Growth curves of pseudomonas in presence of ticarcillin, gentamicin, combined ticarcillin and gentamicin, and when no antibiotic was used 
Table 1 Clinical evaluation and pseudomonas colony count after treatment of experimental pseudomonas keratitis with ticarcillin, gentamicin, combined ticarcillin and gentamicin, and saline solution

\begin{tabular}{|c|c|c|c|c|c|c|c|c|c|c|c|}
\hline \multirow{2}{*}{ Rabbit No. } & \multirow{2}{*}{ Treatment } & \multicolumn{8}{|c|}{ Clinical scores } & \multirow{2}{*}{\multicolumn{2}{|c|}{$\begin{array}{l}\text { Pseudomonas } \\
\text { Colony count } \\
R E \quad \text { LE }\end{array}$}} \\
\hline & & $\begin{array}{l}\text { Day } \\
R E\end{array}$ & $\begin{array}{l}1^{*} \\
L E\end{array}$ & $\begin{array}{l}\text { Day } \\
R E\end{array}$ & $L_{E}^{2}$ & $\begin{array}{l}\text { Day } \\
R E\end{array}$ & $\begin{array}{l}3 \\
L E\end{array}$ & $\begin{array}{l}\text { Day } \\
R E\end{array}$ & $L E$ & & \\
\hline $\begin{array}{l}11 \\
12 \\
13 \\
14 \\
15 \\
16 \\
17 \\
18 \\
19 \\
20 \\
21 \\
22 \\
23 \\
24 \\
25 \\
26 \\
27 \\
28 \\
29 \\
30 \\
31 \\
32 \\
33 \\
34 \\
35 \\
36 \\
37 \\
38\end{array}$ & $\begin{array}{l}\text { Ticarcillin } \\
\text { Gentamicin } \\
\text { Ticarcillin and gentamicin } \\
\text { Saline solution }\end{array}$ & $\begin{array}{l}2 \\
2 \\
2 \\
2 \\
3 \\
2 \\
2 \\
2 \\
2 \\
2 \\
2 \\
2 \\
3 \\
3 \\
2 \\
2 \\
3 \\
2 \\
2 \\
2 \\
2 \\
2 \\
2 \\
2 \\
3 \\
2 \\
2 \\
2\end{array}$ & $\begin{array}{l}2 \\
2 \\
2 \\
2 \\
3 \\
2 \\
2 \\
2 \\
2 \\
2 \\
2 \\
2 \\
3 \\
3 \\
2 \\
2 \\
2 \\
2 \\
2 \\
2 \\
2 \\
2 \\
3 \\
2 \\
2 \\
2 \\
2 \\
2\end{array}$ & $\begin{array}{l}3 \\
2 \\
3 \\
3 \\
3 \\
2 \\
3 \\
3 \\
2 \\
1 \\
2 \\
4 \\
3 \\
3 \\
3 \\
1 \\
2 \\
3 \\
3 \\
2 \\
2 \\
3 \\
4 \\
4 \\
4 \\
3 \\
3 \\
2\end{array}$ & $\begin{array}{l}3 \\
2 \\
3 \\
3 \\
3 \\
2 \\
3 \\
2 \\
3 \\
2 \\
2 \\
4 \\
3 \\
2 \\
2 \\
1 \\
2 \\
2 \\
2 \\
2 \\
3 \\
4 \\
4 \\
4 \\
4 \\
3 \\
3 \\
3\end{array}$ & $\begin{array}{l}2 \\
2 \\
4 \\
4 \\
3 \\
2 \\
3 \\
3 \\
2 \\
1 \\
2 \\
5 \\
4 \\
3 \\
3 \\
0 \\
2 \\
3 \\
3 \\
2 \\
2 \\
4 \\
4 \\
4 \\
4 \\
3 \\
3 \\
3\end{array}$ & $\begin{array}{l}2 \\
2 \\
3 \\
3 \\
3 \\
2 \\
3 \\
3 \\
3 \\
2 \\
2 \\
4 \\
4 \\
2 \\
2 \\
1 \\
2 \\
3 \\
2 \\
2 \\
3 \\
4 \\
4 \\
4 \\
3 \\
3 \\
3 \\
4\end{array}$ & $\begin{array}{l}2 \\
2 \\
4 \\
4 \\
3 \\
2 \\
3 \\
3 \\
2 \\
0 \\
2 \\
4 \\
3 \\
3 \\
3 \\
0 \\
2 \\
3 \\
2 \\
2 \\
2 \\
3 \\
4 \\
5 \\
4 \\
3 \\
4 \\
3\end{array}$ & $\begin{array}{l}2 \\
2 \\
4 \\
4 \\
4 \\
2 \\
3 \\
3 \\
3 \\
2 \\
2 \\
4 \\
3 \\
2 \\
2 \\
1 \\
2 \\
2 \\
2 \\
2 \\
2 \\
3 \\
4 \\
4 \\
4 \\
4 \\
3 \\
3\end{array}$ & $\begin{array}{c}0 \\
2 \\
13 \\
261 \\
7 \\
116 \\
2 \\
0 \\
612 \\
0 \\
0 \\
9 \\
1304 \\
\text { TNTC } \\
65 \\
49 \\
0 \\
0 \\
227 \\
12 \\
1 \\
463 \\
1010 \\
\text { TNTC } \\
\text { TNTC } \\
344 \\
172 \\
0\end{array}$ & $\begin{array}{c}5 \\
\text { TNTC† } \\
45 \\
19 \\
5 \\
13 \\
0 \\
5 \\
0 \\
1 \\
1 \\
280 \\
\text { TNTC } \\
1024 \\
2 \\
0 \\
1034 \\
0 \\
2 \\
0 \\
22 \\
\text { TNTC } \\
\text { TNTC } \\
\text { TNTC } \\
\text { TNTC } \\
\text { TNTC } \\
\text { TNTC } \\
\text { TNTC }\end{array}$ \\
\hline
\end{tabular}

*Postinoculation †Too numerous to count.

groups treated with ticarcillin alone and gentamicin alone was the difference insignificant.

Table 1 also shows the result of pseudomonas colony counts on culture plates prepared at the end of the treatment schedule. (On day 1 after the pseudomonas inoculation-before treatment was started-the organism had been recovered in cultures of corneal material from all of the eyes.)

By Student's $t$ test there was a significant difference between the colony counts of the groups treated with ticarcillin, gentamicin, and the two drugs in combination, and the colony count of the group treated with saline solution $(P<0.01)$; but there was no significant difference by this test among

Table 2 Comparison of clinical scores of 56 rabbit eyes with experimental pseudomonas keratitis on day 4 after beginning of treatment

\begin{tabular}{lllllllll}
\hline \multirow{2}{*}{ Treatment } & $\begin{array}{l}\text { No. of eyes } \\
\text { treated }\end{array}$ & 0 & $1+$ & $2+$ & $3+$ & $4+$ & $5+$ \\
\cline { 2 - 8 } & 14 & $0 *$ & 0 & 6 & 3 & 5 & 0 \\
\hline Ticarcillin & 14 & 1 & 0 & 5 & 6 & 2 & 0 \\
Gentamicin & 14 & 1 & 1 & 10 & 2 & 0 & 0 \\
$\begin{array}{l}\text { Ticarcillin and } \\
\text { gentamicin }\end{array}$ & 14 & 0 & 0 & 0 & 6 & 7 & 1 \\
Saline solution & 14 & 0 &
\end{tabular}

Total number of eyes with this score on day 4 the antibiotic-treated groups, whether treated by one drug alone or by the two combined.

\section{TOXICITY}

In the rabbits injected with the four different doses of ticarcillin (from 10 to $100 \mathrm{mg}$ ) the only noticeable change in the conjunctiva was slight hyperaemia at the site of the injection and an occasional subconjunctival haemorrhage. The cornea remained clear throughout the period of observation. The conjunctival hyperaemia subsided in two days with the lowest dose of ticarcillin, and in seven days with the highest dose. No conjunctival necrosis occurred.

\section{Discussion}

On the basis of their respective MICs against the pseudomonas strain used in this in-vitro experiment ticarcillin was found to be twice as active as carbenicillin-a difference also noted by other investigators (Bodey and Deerhake, 1971; Mai and Bulow, 1974).

When ticarcillin and gentamicin were combined in vitro, there was a 100-fold reduction in the growth of the organism after 24 hours' incubation (Fig. 1). This effect was clearly additive-and possibly synergistic. Penicillin and gentamicin are known to be synergistic when used together against enterococci 
(Moellering et al., 1973). The cell-wall inhibitor (penicillin) facilitates the passage of the aminoglycoside (gentamicin) into the cytoplasm of the bacterial cell. Ultimately a lethal concentration is reached and ribosomal protein synthesis is blocked.

In comparing the in-vivo results it should be emphasised that the doses we used were lower than the therapeutic doses of these drugs. But even with these low doses there were significant clinical differences between the ticarcillin- and gentamicintreated groups and the group treated with saline solution. The best results were obtained when the ticarcillin and gentamicin were combined.

The culture plates prepared at the end of the treatment period showed a significant suppression of the growth of the organism in the groups treated with ticarcillin, gentamicin, or the two drugs in combination, in comparison with the group treated with saline solution. Although there was no significant difference in the colony counts between the group treated with the antibiotics in combination and the groups treated with each antibiotic alone, there were fewer colonies in the combination group, and on none of the plates in this group was the growth confluent.
Ticarcillin by itself seems to be a promising antibiotic for the treatment of pseudomonas keratitis in rabbits. The advantage of combining it with gentamicin is that the amount of each antibiotic can then be reduced and the risk of toxicity minimised.

Ticarcillin is readily soluble in water and can be given systemically in doses of up to $20 \mathrm{~g} /$ day (Wise and Reeves, 1974). The only adverse effect noted so far is the pain the drug may cause at the injection site when it is given intramuscularly.

\section{References}

Bodey, G. P., and Deerhake, B. (1971). Applied Microbiology, 21, 61.

Davies, M., Morgan, J. R., and Anand, C. (1974). Chemotherapy, 20, 339.

Mai, K., and Bulow, B. (1974). Infection, 2, 12.

Maliwan, N., Grieble, H. G., and Bird, T. J. (1975). Antimicrobial Agents and Chemotherapy, 8, 415.

Moellering, R. C., Wennersten, C., and Weinstein, A. J. (1973). Antimicrobial Agents and Chemotherapy, 3, 526.

Neu, H. C., and Garvey, G. J. (1975). Antimicrobial Agents and Chemotherapy, 8, 457.

Smolin, G., Okumoto, M., and Wilson II, F. (1974). American Journal of Ophthalmology, 77, 583.

Wise, R., and Reeves, D. S. (1974). Chemotherapy, 20, 45. 